\title{
Barriers to the Success of Ethnic Minority Students in School Psychology Graduate Programs
}

\author{
Chelsi R. Clark \\ The University of Southern Mississippi \\ Sterett H. Mercer \\ University of British Columbia \\ Virgil Zeigler-Hill \\ Oakland University \\ Brad A. Dufrene \\ The University of Southern Mississippi
}

\begin{abstract}
The current study examined factors that may serve as barriers to the success of ethnic minority graduate students by assessing the academic, social, and emotional experiences of approximately 87 ethnic minority and 313 ethnic majority school psychology graduate students. Results indicated that ethnic minority graduate students reported significantly more negative race-related experiences, which were associated with higher levels of emotional distress, than were ethnic majority graduate students. In addition, ethnic minority graduate students reported lower levels of belongingness than did ethnic majority students' and negative race-related experiences were associated with lower perceptions of belongingness across all participants. Belongingness and autonomy were significantly associated with self-reported academic engagement for both ethnic minority and majority students. Discussion focuses on the significance of racial microaggressions and belongingness to graduate students in school psychology programs.
\end{abstract}

Developing methods to increase the number of ethnic minority school psychologists is critically important to the future of the profession (e.g., Davis, McIntosh, Phelps, \& Kehle, 2004; Fagan, 1988). Survey data from the National Association of School Psychologists (NASP) for the 2004-2005 school year indicated that only $7.4 \%$ of school psycholo- gists identified themselves as belonging to an ethnic minority group (Curtis et al., 2008). This is important because disparities between the ethnicities of school psychologists and the clients they serve may impair their ability to relate to their clients and provide appropriate services (Thompson \& Alexander, 2006; Yeh, Eastman, \& Cheung, 1994). For these reasons,

Correspondence concerning this article should be addressed to Sterett H. Mercer, 2125 Main Mall, Vancouver, BC V6T 1Z4, Canada; e-mail: sterett.mercer@ubc.ca

Copyright 2012 by the National Association of School Psychologists, ISSN 0279-6015 
it is essential for training programs in school psychology to focus more of their efforts on recruiting and retaining ethnic minority students. However, ethnic minority students in school psychology programs often face a number of challenges such as a lack of culturally similar mentors, insufficient undergraduate preparation, limited financial support, and nonoptimal institutional climate (Zhou et al., 2004).

Of the different forms of race-related experiences that may impact the functioning and engagement of ethnic minority graduate students, racial microaggressions may be among the most important. Racial microaggressions are "brief, everyday exchanges that send denigrating messages to people of color because they belong to a racial minority group...often unconsciously delivered in the form of subtle snubs, or dismissive looks, gestures, and tones" (Sue et al., 2007, p. 273). Microaggressions were initially described by Pierce (1969) to characterize cross-racial interactions, but have been extended to gender and sexual orientation (Shelton \& DelgadoRomero, 2011). Some researchers have minimized the importance of microaggressions by characterizing them as simple misattributions or misunderstandings that can be made by either ethnic majority or minority individuals (e.g., Schacht, 2008; Thomas, 2008). Despite these criticisms, recent research has found that racial microaggressions are associated with important outcomes in the lives of ethnic minority individuals (e.g., stress, psychological adjustment; Mercer, Zeigler-Hill, Wallace, \& Hayes, 2011).

Microaggressions take three primary forms: microinsults, microassaults, and microinvalidations (Sue et al., 2007). Microinsults are race-based statements that are rude and demeaning to a person (e.g., comments such as "You are so articulate" that can imply a sense of surprise that an ethnic minority student can speak intelligently or reacting in an overly positive manner to statements by ethnic minority students during class discussions). Microassaults are more blatant forms of racism that are meant to insult or hurt the intended victim (Sue et al., 2007) and may be verbal (e.g., referring to an ethnic minority student using a racial slur), behavioral (e.g., deliberately providing assistance to an ethnic majority student while making an ethnic minority student wait), or environmental (e.g., posting racially insensitive posters or signs in an area frequented by ethnic minorities). $M i$ croinvalidations are statements or actions that invalidate or nullify a person's feelings, experiences, or beliefs based on his or her race (e.g., making a comment in class that the most qualified students should get into college during a discussion about minority scholarships or statements that minimize race such as "I don't see race when I look at you; I just see a human being"). Microaggressions may be important to ethnic minority graduate students because these experiences could cause additional stress during an already demanding time in their lives. To further complicate the experiences of ethnic minority graduate students, the subtle nature of microaggressions may leave them uncertain as to whether they are being overly vigilant or experiencing "healthy paranoia" (Sue, Capodilupo, \& Holder, 2008, p. 332).

Microaggressions have been studied across various ethnic minority groups. Several microinsult themes have been described in focus groups of African American college students and staff, such as perceptions that they were treated as if they were (a) less intelligent than ethnic majority individuals, (b) secondclass citizens, (c) potential criminals, or (d) from an inferior culture (Sue, Nadal et al., 2008). Several microinvalidation themes were also identified, including assumptions by ethnic majority individuals that (a) all African Americans have the same experiences throughout life so that one person can represent the group and (b) race is unimportant to the individual or life in general (Sue, Nadal et al., 2008). In similar studies conducted to explore the racial microaggression experiences of Asian Americans and Latino(a)s, themes similar to those reported by African Americans emerged along with some group-specific themes (Sue, Bucceri, Lin, Nadal, \& Torino, 2009; Yosso, Smith, Ceja, \& Solórzano, 2009). Although there may be group differ- 
ences with regard to experiences with microaggressions, some experiences are common across groups and these experiences may be psychologically damaging and may contribute to racial disparities in employment, education, and health care (see Sue, 2010, for a review). In particular, experiencing microaggressions may undermine perceptions of belongingness and autonomy, which may be detrimental to the performance of ethnic minority graduate students because these factors have been identified as important to educational success (Van Ryzin, Gravely, \& Roseth, 2009).

\section{Self-Determination Theory}

Perceptions of social belongingness and autonomy have been described in self-determination theory (Deci, Vallerand, Pelletier, \& Ryan, 1991) as fundamental needs that support life happiness and success. The need for social belongingness also extends to the realm of higher education where belongingness is a crucial factor in student success (Walton \& Cohen, 2007). Belongingness may be particularly important for ethnic minority students because they are underrepresented in higher education. Ethnic minority students in higher education have shared that peer support and faculty mentorship provided them with the support they needed to thrive in academia despite the barriers they faced as ethnic minorities (Vasquez et al., 2006). Ethnic minority undergraduate students have reported that they tend to feel more comfortable in ethnic majority academic environments when they are not the only minority student, feel respected by their peers, and do not experience intolerance or prejudice (Booker, 2007). Faculty mentorship is another important way in which feelings of belongingness may be fostered among graduate students. It is important to note that ethnic matches between mentormentee dyads are not necessary for building an effective relationship (Burney et al., 2005) because mentors can encourage feelings of belongingness through various methods (e.g., not assuming that they have had identical experiences as their protégés, encouraging students to celebrate their diversity, directly ad- dressing issues of race, considering how race affects students' sense of belongingness and academic achievement; Davidson \& FosterJohnson, 2001).

In addition to belongingness, self-determination theory includes autonomy as a necessary factor for academic success. Environmental stressors can significantly impact perceptions of autonomy (Lambert, Herman, Bynum, \& Ialongo, 2009), and both stressors and perceptions of autonomy influence persistence in educational programs (Davis, Johnson, Cribbs, \& Saunders, 2002). There is only one NASP-approved school psychology graduate program located on the campus of a Historically Black College and University (HBCU), which suggests that most ethnic minority graduate students are receiving their education in environments that highlight the salience of their minority status (National Association of School Psychologists, 2010). Ethnic minority students in predominantly ethnic majority environments often report psychological and physiological stress, feel the need to remain hypervigilant, and experience mental exhaustion and burnout (Smith, Allen, \& Danley, 2007). Ultimately, this stress could contribute to lower perceptions of autonomy and belongingness in ethnic minority graduate students with these factors, in turn, contributing to emotional distress among ethnic minority graduate students.

\section{Emotional Distress}

Although ethnic minority graduate students may be unlikely to experience overt racism on university campuses, the psychological effects of racial microaggressions can be as severe as those of overt racism (Smith et al., 2007). In a survey of African American undergraduate students in predominantly ethnic majority universities, students reported that they felt overlooked and underestimated in classroom settings and that their experiences on these campuses made them feel so isolated and insecure that some had considered changing universities (Solórzano, Ceja, \& Yosso, 2009). Similarly, Latino(a) undergraduate students have reported that experiences with ra- 
cial microaggressions have led to feelings of isolation, rejection, and race-related stress (Yosso et al., 2009), and both Latino(a) and Asian American college students reporting greater amounts of perceived discrimination have exhibited greater symptoms of depression and anxiety (Hwang \& Goto, 2008). In a study of African American adolescents, Lambert et al. (2009) found that perceived racism had indirect effects on depression that were mediated through perceptions of autonomy (Lambert et al., 2009). Consequently, racial microaggressions, via feelings of inadequacy, isolation, and loss of autonomy, can contribute to emotional distress. We believe it is possible that the combination of these factors may impact students' academic engagement and subsequent outcomes.

\section{Academic Engagement}

Academic engagement is a strong predictor of academic outcomes (see Fredricks, Blumenfeld, and Paris, 2004, for a review), and experiences with racial microaggressions may negatively impact the academic engagement of ethnic minority students. For example, many ethnic minority students feel like they are viewed as outsiders or are invisible in predominantly ethnic majority educational environments (Solórzano et al., 2009). African American male undergraduate students, in particular, feel like they are marginalized on their campuses and are not only treated as outsiders but as potential criminals (Smith et al., 2007). Dealing with daily microaggressions, as well as feelings of alienation and powerlessness, can cause mental exhaustion that ultimately affects a student's ability to put forth the mental and physical effort needed to fully academically engage (Solórzano et al., 2009).

\section{Focus of the Current Study}

Previous studies have examined factors that serve as barriers to the educational success of minority students, but research has yet to investigate the negative race-related experiences of school psychology graduate students or address whether those experiences are associated with academic engagement and emotional distress. In this study, we sought to determine whether (a) ethnic minority students will experience more negative race-related experiences than ethnic majority students, (b) negative race-related experiences will be associated with lower perceptions of belongingness and autonomy, and (c) lower perceptions of belongingness and autonomy will be associated with greater emotional distress and less academic engagement. In addition, we examined the extent to which experiencing racial microaggressions is indirectly associated with emotional distress and less academic engagement via lower perceptions of belongingness and autonomy. Models were compared across ethnic minority and majority graduate students to explore the extent to which these associations differ as a function of ethnicity.

\section{Method}

\section{Participants}

Participants in the study included 400 school psychology graduate students. The approximate ethnic distribution was $78.3 \%$ European American $(n=313), 9.8 \%$ Hispanic American $(n=39), 5.5 \%$ African American $(n=22), 5.8 \%$ Asian American $(n=23)$, and $0.8 \%$ Native American $(n=3)$. The mean age of ethnic minority graduate students $(n=$ 87 ) was $26.64(S D=4.94)$. Most ethnic minority graduate students were pursuing doctoral degrees $(n=46 ; 52.9 \%)$. Sixteen percent of ethnic minority graduate students were men. Of the ethnic minority graduate students, $32(37 \%)$ were in their first year of graduate training, $21(24 \%)$ in their second year, $15(17 \%)$ in their third year, and 19 $(22 \%)$ in their fourth year or later. Regarding campus location, 41 (47\%) ethnic minority graduate students described their campus as in an urban area, with 32 (37\%) and 14 (16\%) describing their campus as in a suburban or rural location, respectively. The mean age of ethnic majority $(n=313)$ graduate students was $26.04(S D=5.03)$. A large proportion of ethnic majority graduate students were pursuing doctoral degrees $(n=153 ; 48.9 \%)$. Fifteen percent of ethnic majority graduate students 
were men. The reported year of graduate training was the following for ethnic majority graduate students: first $(n=126,40 \%)$, second $(n=68,22 \%)$, third $(n=66,21 \%)$, or fourth or greater $(n=53,17 \%)$. Ethnic majority students described their campus location as the following: urban $(n=128,41 \%)$, suburban $(n=128,41 \%)$, or rural $(n=57,18 \%)$.

\section{Measures}

Racial microaggressions. Racial microaggression experiences were assessed using the Inventory of Microaggressions against Black Individuals (IMABI; Mercer et al., 2011), consisting of 14 items that measure experiences with and perceptions of covert racism. The IMABI has been primarily used with African American undergraduate samples, and assesses seven aspects of racial microaggressions including ascription of intelligence ("I was made to feel that my achievements were primarily due to preferential treatment based on my racial/ethnic background"), assumption of inferior status ("Someone assumed I was a service worker or laborer because of my race/ethnicity"), assumption of criminality ("I was followed in a store due to my race/ethnicity"), assumed superiority of White cultural values ("Someone reacted negatively to the way I dress because of my racial/ethnic background"), assumed universality of the ethnic minority experience ("Someone asked my opinion as a representative of my race/ethnicity"), denial of individual racism/colorblindness ("Someone made a statement to me that they are not racist or prejudiced because they have friends from different racial/ethnic backgrounds"), and myth of meritocracy ("Someone told me that everyone can get ahead if they work hard when I described a difficulty related to my racial/ ethnic background").

Each item of the IMABI is rated on a 5 -point scale $(0=$ This has never happened to me, 1 = This event happened but I was not upset, 2 = This event happened and I was slightly upset, 3 = This event happened and I was moderately upset, and $4=$ This event happened to me and I was extremely upset).
The response format combines frequency with severity of emotional response and is commonly used in measures of general stress (e.g., Daily Hassles Scale; Kanner, Coyne, Schaefer, \& Lazarus, 1980) and race-related stress (e.g., Index of Race-Related Stress; Utsey, 1999). Reported internal consistency for the IMABI total score is .94 in an African American undergraduate sample (Mercer et al., 2011) and was .89 and .80 for ethnic minority and majority graduate students, respectively, in the current sample. Validity for this instrument is supported by relations of the IMABI to scores on measures assessing racerelated stress, racial identity, anticipated racial discrimination, and psychological distress (Mercer et al., 2011).

Although the IMABI assesses forms of microaggressions that may not be experienced directly in the graduate school program or perpetrated by program faculty or students (e.g., assumption of criminality), it is possible these experiences could occur on the university campus or in the surrounding community. Consequently, we did not limit our investigation to microaggressions experienced solely in the immediate context of graduate training.

Belongingness. Belongingness was assessed using subscales of the Classroom Life Scale (CLS; Johnson, Johnson, Buckman, \& Richards, 1985) that measure perceptions of social support from teachers and peers. The CLS has been primarily used in secondary and undergraduate student samples, so some of the subscale items were originally worded to refer to "in this class" and "teachers" but we altered these items to refer to "in this program" and "graduate trainers" for the present study. Only the following subscales of the CLS were used in the present study: Student Personal Support (5 items, sample item: "In this program, other students really care about me"), Student Academic Support (4 items, sample item: "In this program, other students care about how much I learn"), Teacher Personal Support (4 items, sample item: "My graduate trainers like me as much as they like other students"), and Teacher Academic Support (4 items, sample 
item: "My graduate trainers want me to do my best").

Each item is rated on a 5-point scale $(1=$ completely false and $5=$ completely true). A principal components analysis of these scales found a two-factor solution: teacher support and peer support (Van Ryzin et al., 2009). Because of our interest in overall perceptions of support and belongingness in this study, we averaged across items on the teacher and peer support subscales, which resulted in estimates of internal consistency of .96 and .94 in ethnic minority and majority students, respectively. In the current study, reports of teacher and peer support were highly correlated $(r=.59, p<.001)$, and results did not substantively differ when the teacher and peer support factors were analyzed instead of the combined belongingness factor. Validity of the measure is supported by studies linking belongingness as measured by the CLS to academic engagement and student adjustment (Van Ryzin et al., 2009).

Autonomy. Sense of autonomy was assessed using the Psychological Well-Being Scales-Short Forms (PWBS-SF; Ryff \& Keyes, 1995). For this study, only the subscales of Autonomy (14 items, sample item: "My decisions are not usually influenced by what everyone else is doing") and Environmental Mastery (13 items, sample item: "In general, I feel I am in charge of the situation in which I live") were used. Some of the scale items on the Autonomy subscale were altered to include the words "in my program" at the end of the item. Each item is rated on a 6-point scale $(1=$ strongly disagree and $6=$ strongly agree). We were interested in overall levels of autonomy so we averaged across items on the Autonomy and Environmental Mastery subscales, yielding an internal consistency estimate of 0.87 for ethnic minority graduate students and 0.89 for ethnic majority students. Validity for this instrument is supported by studies linking scores on the PWBS-SF to life satisfaction, affective balance, self-esteem, internal control, depression, and morale (Ahrens \& Ryff, 2006; Ryff, 1989; Schmutte \& Ryff, 1997). Studies have provided evidence of the reliability and validity of the PWBS-SF in multiple age groups (e.g., young adolescents, college students, older adults) and cultures (see Ryff \& Singer, 2006).

Emotional distress-perceived stress. Level of perceived stress was assessed using the Perceived Stress Scale (PSS; Cohen, Kamarck, \& Mermelstein, 1983). The PSS is a 14-item scale that measures the extent to which one perceives life situations as stressful. Sample items include "In the last year, how often have you felt difficulties were so high you could not overcome them?" and "In the past year, how often have you felt nervous and stressed?" Each item is rated on a 5-point scale $(1=$ never and $5=$ very often $)$. Internal consistency estimates from the current sample were .83 and .86 for ethnic minority and majority graduate students, respectively. Validity for this instrument is supported with studies linking high scores on the PSS to high scores on scales used to assess psychological distress, depressive symptoms, and stress-induced physical symptoms (Cohen et al., 1983; Cohen \& Williamson, 1988). The PSS is a widely used instrument that has been employed to assess stress in samples of adolescents and adults across a variety of cultures.

\section{Emotional distress-depression and} anxiety. Levels of depression and anxiety were assessed using the Brief Symptom Inventory (Derogatis, 1975), which consists of 53 items that measure recent distress. In this study, only the subscales of Depression (6 items, sample item: "Feeling fearful") and Anxiety (6 items, sample item: "Feeling lonely") were used. Each item is rated on a 5-point scale that ranged from 0 (not at all) to 4 (extremely). Internal consistency for scores on Depression was .87 and .90 for ethnic minority and majority graduate students, respectively. For Anxiety, estimates of internal consistency were .70 and .80 for ethnic minority and majority graduate students, respectively. Concurrent validity for this instrument is supported by positive correlations with domain scores on the Minnesota Multiphasic Personality Inventory (Boulet \& Boss, 
1991; Derogatis \& Melisaratos, 1983). The reliability and validity of the Brief Symptom Inventory has been supported in studies across multiple age groups, subpopulations, and cultures.

Academic engagement. Academic engagement was assessed using the Student Course Engagement Questionnaire (Handelsman, Briggs, Sullivan, \& Towler, 2005), which was originally developed to identify four components of academic engagement in undergraduate courses: Emotional Course Engagement (10 items, sample item: "Doing all the assignments"), Participation/Interaction Course Engagement (5 items, sample item: "Asking questions when I don't understand the instructor"), Performance Course Engagement (4 items, sample item: "Participating actively in group discussions"), and Skills Course Engagement (4 items, sample item: "Getting a good grade"). Each item is rated on a 5 -point scale $(1=$ not at all characteristic of me and $5=$ very characteristic of me). Internal consistency for scores from the current sample of ethnic minority students were .80 , $.78, .73$, and .86 , respectively, and $.83, .64$, .69 , and .83 for ethnic majority students. Validity of this instrument is supported by correlations of Student Course Engagement Questionnaire factors with measures assessing level of academic challenge, affective components of engagement, faculty interaction, and extrinsic motivation in undergraduate students (Handelsman et al., 2005).

\section{Procedure}

An Internet-based survey was used to collect the data. As an incentive to participate, all graduate students were given the chance to enter four raffle drawings for $\$ 25$ each. Graduate students were recruited via an e-mail announcement of the study sent to training directors of school psychology programs and listservs of student organizations, including Student Affiliates in School Psychology, the NASP Interest Group for Students of School Psychology, and NASP Interest Group for Multicultural Issues. Graduate students used a hypertext link to gain access to the survey
Web site. After reading the informed consent, graduate students were instructed to report demographic information and complete survey measures with the racial microaggression measure administered last so that responses to other measures would be less impacted by this potentially sensitive measure.

\section{Data Analyses}

Prior to investigating the structural relations among latent variables, measurement invariance was tested across ethnic minority and majority samples. Several latent constructs were specified for use in a structural equation model (see Figure 1) with the following indicators: racial microaggressions (three parcels formed by randomly assigning items to parcels), belongingness (three parcels formed by randomly assigning items from the CLS peer and teacher support factors to parcels), autonomy (three parcels formed by randomly assigning items from the PWBS autonomy and environmental mastery subscales to parcels), emotional distress (perceived stress from the PSS total score and the depression and anxiety subscales from the Brief Symptom Inventory as indicators), and academic engagement (emotional, participation/interaction, performance, and skills engagement subscales from the Student Course Engagement Questionnaire as indicators). Although parcels are not recommended for analyses focused on the psychometric properties of individual measures (e.g., confirmatory factor analysis; Little, Cunningham, Shahar, \& Widaman, 2002), they can be used when the focus is primarily on structural relations among latent variables. The use of parcels, in this context, is preferred over analytic approaches that do not account for measurement error such as multiple regression or path analysis (Coffman \& MacCallum, 2005). Survey participants tend to report few experiences of microaggressions (Mercer et al., 2011), which violates the assumption of multivariate normality for maximum likelihood estimation in structural equation modeling (SEM). Thus, standard errors of model parameters were estimated using bootstrap resampling (10,000 samples), which is robust to 


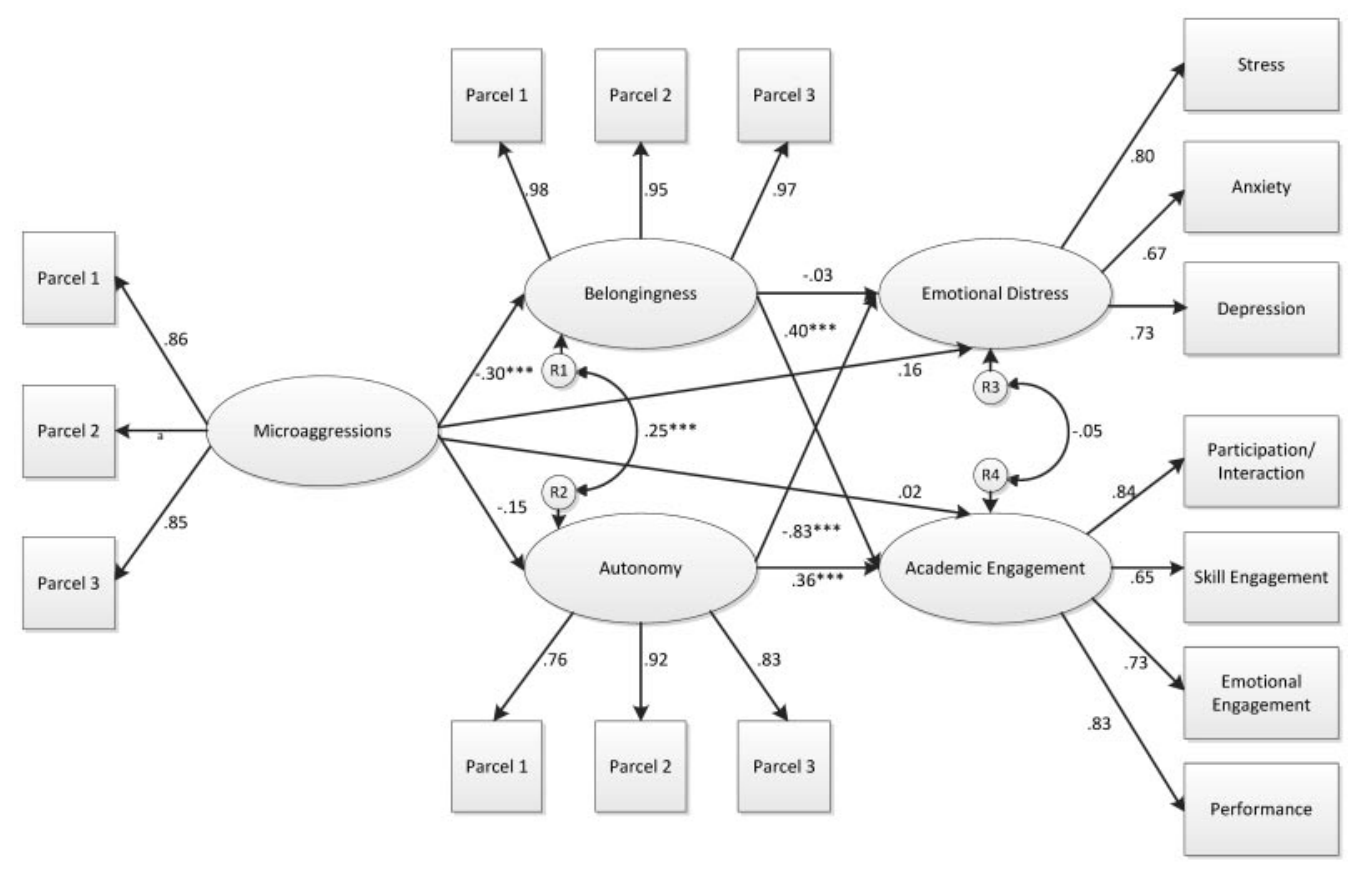

Figure 1. Structural model of microaggressions with emotional distress and academic engagement as mediated by perceptions of belongingness and autonomy. All displayed coefficients are standardized. a Loading varied across groups (ethnic minority $=.89$; ethnic majority $=.74$ ). The $p$ values are only provided for structural paths and covariances. $* * * * p<.001$

departures from normality (Nevitt \& Hancock, 2001).

To test measurement invariance, a model with factor loadings and indicator intercepts that were free to vary across groups was compared to models with weak factorial invariance (i.e., equal loadings across groups) and strong factorial invariance (i.e., equal loadings and intercepts across groups). The nested models were compared based on the following criteria: (a) change in comparative fit index (CFI) between models with change $\leq .005$ suggesting invariance and (b) change in root mean square error of approximation (RMSEA) with change $\leq .01$ suggesting invariance (Chen, 2007). For analyses with unequal group sizes, these criteria are less sensitive to invariance (Chen, 2007); consequently, inspection of model modification indices was also used to identify loadings and intercepts that may have varied substantially across groups. In multiple-group SEM, determination of measurement invariance is important to rule out the possibility that observed differences between groups on regression weights or latent mean differences are not an artifact of varying psychometric properties for measures across groups.

Following determination of measurement invariance, all research questions were investigated via the model depicted in Figure 1. The first research question was addressed by examining the statistical significance of the mean of the latent microaggression variable in the ethnic majority group relative to the ethnic minority group. In multiple-group SEM, the means and intercepts of the latent variables of a reference group (i.e., the ethnic minority group) are constrained to equal zero for identification purposes; consequently, the values for the means and intercepts of latent variables in the ethnic majority 
group represent the differences between groups, and the statistical significance of these values are tests of differences across groups. The second and third research questions were examined by inspecting the statistical significance of the structural regression weights in the model.

The degree to which (a) structural regression weights, (b) the residual correlation between belongingness and autonomy, and (c) the residual correlation between emotional distress and academic engagement differed across ethnic minority and majority groups was determined by comparing changes in model fit based on the previously presented criteria after the imposition of equality constraints. The statistical significance of mediated relations was determined using bias-corrected, bootstrapped confidence intervals, a recommended technique to assess mediation (Cheung \& Lao, 2008; MacKinnon, Lockwood, \& Williams, 2004). Fit of the final model was assessed, in addition to the previously discussed comparisons of relative model fit, using $\mathrm{Hu}$ and Bentler's (1999) criteria: CFI $>$.95, Tucker-Lewis Index $($ TLI $)>.95$, and RMSEA $<.06$. All models were fit in Mplus 6.11 (Muthén \& Muthén, 1998-2010).

Participants with missing data were included in all analyses. The percentage of participants with complete data on individual items ranged from $82 \%$ to $100 \%(M=88 \%$, $S D=6 \%$ ). Missing data were handled by maximum likelihood estimation, which uses all available information to calculate parameter estimates. Research suggests that this approach to addressing missing data are less biased than other commonly used techniques such as mean substitution or list-wise deletion (Enders, 2010).

Unequal group sizes can have an impact results in multiple-group standard error of the mean (SEM; Lubke \& Dolan, 2003), so we also conducted all of our analyses with a randomly selected subset of the ethnic majority graduate students that was equal in size to the sample of ethnic minority graduate students (i.e., 87 ethnic minority and 87 ethnic majority graduate students). Substantive results were unaffected by this specification, including in- ferences regarding measurement invariance, invariance of structural paths, and statistical significance of structural regression weights. For parsimony, only the results based on the full sample are reported; however, the sensitivity analyses with equal subgroup sizes suggest that the results were minimally impacted by unequal numbers of ethnic minority and majority students.

\section{Results}

\section{Measurement Invariance}

Descriptive statistics (i.e., means and standard deviations for all indicators) by student group are presented in Table 1. Prior to examining relations among constructs, we assessed the relative fit of models that tested measurement invariance across ethnic minority and majority graduate students. The baseline model (all factor loadings and intercepts free to vary across groups) appeared to adequately fit the data based on values of approximate fit indices: $\chi^{2}(188)=279.77, p<.001$; $\mathrm{CFI}=.977$; TLI $=.971 ;$ RMSEA $=.049$. The next model tested equality of factor loadings across groups, and estimates of change in CFI (.011) and RMSEA (.008) were near values that would suggest invariance of factor loadings based on Chen's (2007) criteria; however, inspection of model modification indices suggested that the loading on the second microaggression parcel significantly varied across groups. With the loading on this parcel free to vary across groups, change in CFI (.002) and RMSEA (.001) was negligible. Finally, a model was fit with all loadings and indicator intercepts, excluding the second microaggression parcel, constrained to be equal across ethnic minority and majority students. Change in CFI (.003) and RMSEA (.001) indicated minimal worsening of fit with these constraints, supporting partial measurement invariance across groups. Consequently, this partially invariant measurement model (i.e., one factor loading and intercept free to vary across groups) was used to investigate structural relations among latent variables. 


\section{Table 1}

Means and Standard Deviations by Variable and Student Group

\begin{tabular}{lccccc}
\hline & \multicolumn{2}{c}{$\begin{array}{c}\text { Ethnic Minority } \\
\text { Graduate Students }\end{array}$} & & \multicolumn{2}{c}{$\begin{array}{c}\text { Ethnic Majority } \\
\text { Graduate Students }\end{array}$} \\
\cline { 2 - 3 } & $M$ & & & & $S D$ \\
\hline Racial Microaggressions (P1) & 1.70 & 0.70 & & 1.24 & 0.37 \\
Racial Microaggressions (P2) & 1.84 & 0.86 & & 1.16 & 0.34 \\
Racial Microaggressions (P3) & 1.48 & 0.59 & & 1.17 & 0.32 \\
Belongingness (P1) & 4.54 & 1.07 & & 4.84 & 0.73 \\
Belongingness (P2) & 4.52 & 0.99 & & 4.85 & 0.66 \\
Belongingness (P3) & 4.43 & 1.01 & & 4.84 & 0.77 \\
Autonomy (P1) & 4.32 & 0.60 & & 4.19 & 0.71 \\
Autonomy (P2) & 4.40 & 0.60 & & 4.28 & 0.70 \\
Autonomy (P3) & 4.43 & 0.66 & & 4.31 & 0.68 \\
ED: Perceived Stress & 2.59 & 0.43 & & 2.66 & 0.51 \\
ED: Anxiety & 1.38 & 0.43 & & 1.50 & 0.62 \\
ED: Depression & 1.40 & 0.58 & & 1.49 & 0.77 \\
AE: Participation/Interaction & 3.82 & 0.65 & 3.91 & 0.72 \\
AE: Skill & 4.53 & 0.55 & & 4.46 & 0.60 \\
AE: Emotional & 4.07 & 0.54 & & 4.06 & 0.51 \\
AE: Performance & 3.65 & 0.72 & 3.69 & 0.74 \\
\hline
\end{tabular}

Note. $\mathrm{P} 1=$ Parcel 1, $\mathrm{P} 2=$ Parcel 2, $\mathrm{P} 3=$ Parcel 3, $\mathrm{ED}=$ Emotional Distress, $\mathrm{AE}=$ Academic Engagement.

\section{Reports of Microaggressions}

The mean of the latent microaggression variable in the ethnic majority group $(M=$ $-1.96, S D=1.57)$, which is scaled relative to the mean in the ethnic minority group (constrained to equal zero in multiple-group SEM, $S D=2.99)$, was statistically significant $(p<$ $.001)$, indicating differences across groups. This mean difference (1.96) divided by the sample-size weighted averaged of the latent variable standard deviations (2.38) yielded a standardized mean difference of 0.82 , which is of large magnitude based on Cohen's (1988) guidelines. Although not included in the research questions, differences between ethnic minority and majority groups on all other constructs were also examined. Reports of belongingness significantly differed $(p=.04)$ across ethnic majority $(M=0.25, S D=0.81)$ and minority graduate students $(M$ constrained to zero, $S D=1.04$ ). Specifically, ethnic majority graduate students' reports of belonging- ness were $0.25 S D$ higher than ethnic minority graduate students' reports, and this difference is of small magnitude. Reports of autonomy, emotional distress, and academic engagement did not significantly differ across groups.

\section{Structural Paths}

To determine the extent to which the structural paths and covariances among latent variables differed across ethnic minority and ethnic majority students, the paths and covariances were constrained to be equal across groups. Imposition of the equality constraints resulted in negligible change in CFI (.001) and RMSEA $(<.001)$ as compared to the partially invariant measurement model, indicating that structural paths and covariances did not differ across groups. Approximate fit indices for the constrained model continued to be acceptable, $\chi^{2}(217)=324.96, p<.001 ;$ CFI $=.973$; $\mathrm{TLI}=.970 ;$ RMSEA $=.050$. Because structural paths and covariances did not vary across 
ethnic minority and majority students, the following results are indicative of both groups of graduate students.

As indicated by the standardized beta weights presented in Figure 1, reports of microaggressions by ethnic minority and majority graduate students were associated with belongingness $(\beta=-.30, p<.001)$ but not autonomy $(\beta=-.15, p=.19)$. Specifically, graduate students reporting more experiences of microaggressions reported lower levels of belongingness. Although reports of microaggressions were not independently associated with academic engagement $(\beta=.02, p=.80)$, belongingness was independently associated with academic engagement $(\beta=.40, p<$ .001). Lower perceptions of belongingness were not independently associated with emotional distress $(\beta=-.03, p=.61)$. In contrast, autonomy was independently associated with both academic engagement $(\beta=.36, p<$ $.001)$ and emotional distress $(\beta=-.83, p<$ $.001)$. These results suggest that the higher a graduate student's sense of belongingness and autonomy, the more likely he or she was to report being academically engaged. In addition, graduate students reporting higher levels of autonomy were less likely to report current emotional distress.

As exploratory tests of mediation, the statistical significance of indirect associations (i.e., microaggressions with emotional distress and academic engagement via perceptions of autonomy and belongingness) was examined by inspecting bootstrapped confidence intervals to determine whether they contained zero, which would indicate the indirect association is not statistically significant. Of the possible indirect associations, only one was statistically significant. Specifically, the $99 \%$ confidence interval for the indirect association of microaggressions with academic engagement via belongingness $(-.23$ to -0.01$)$ lends preliminary evidence that the negative association between microaggressions and academic engagement may be mediated by perceptions of belongingness $(p<.01)$.

Regarding the two residual correlations included in the model, belongingness was positively correlated with autonomy $(r=.25, p<$
.001) after accounting for variance attributable to microaggressions; however, emotional distress was unrelated to academic engagement $(r=-.05, p=.63)$ after accounting for variance attributable to other latent variables in the model. Regarding effect size, reports of microaggressions explained $9 \%$ and $4 \%$ of the variance in belongingness for ethnic minority and majority graduate students, respectively, and autonomy explained $77 \%$ and $69 \%$ of the variance in emotional distress, respectively. In addition, belongingness and autonomy in combination explained $37 \%$ and $33 \%$ of the variance in academic engagement for ethnic minority and majority graduate students, respectively.

\section{Discussion}

The goal of the present study was to answer several questions concerning the associations between negative race-related experiences and the academic and emotional functioning of school psychology graduate students. Specifically, we sought to determine the extent to which self-determination theory is useful in explaining the academic engagement and emotional distress of school psychology graduate students as well as the extent to which racial microaggressions relate to graduate students' perceptions of autonomy and belongingness. By conducting analyses across both ethnic minority and majority graduate students, we were able to determine the extent to which results generalize across groups.

\section{Negative Race-Related Experiences of Graduate Students}

The first research question focused on differences in race-related experiences between ethnic minority and majority graduate students in school psychology programs. Results indicated that although both groups reported low levels of racial microaggressions, ethnic minority graduate students reported higher levels than majority graduate students. Common places that people experience racial microaggressions include work and school (Sue et al., 2007). This is especially concerning as perceived racial tensions and experi- 
ences of microaggressions on university campuses have direct effects on students' perceptions of belongingness (Locks, Hurtado, Bowman, \& Oseguera, 2008), self-reported academic engagement and performance (Solórzano et al., 2009), and emotional distress (Hwang \& Goto, 2008; Smith et al., 2007). Consistent with the general patterns of results in this prior research, ethnic minority graduate students in the current study reported lower perceptions of belongingness in their graduate programs than ethnic majority students.

\section{Belongingness and Autonomy}

The second research question focused on the relationship between microaggressions, belongingness, and autonomy. Our findings indicated that although microaggressions are related to lower perceptions of belongingness for both ethnic minority and majority graduate students, microaggressions were unrelated to autonomy. The negative relation between microaggressions and belongingness indicates that the more graduate students encounter negative race-related experiences, the less likely they are to perceive social support in their academic environment.

The relation between microaggressions and belongingness in ethnic majority graduate students was unexpected given that the literature on racial microaggressions has focused primarily on of the experiences of ethnic minorities. Although not specifically assessed in the current study, it is possible that ethnic majority graduate students' reports of racial microaggressions could be a negative reaction to multicultural training. Multicultural training increases multicultural knowledge for most ethnic majority students; however, students high in color-blind racial attitudes (i.e., denial of the significance of race in U.S. society) experience minimal growth in multicultural awareness during multicultural training (Chao, Weis, Good, \& Flores, 2011). Research has documented negative emotional reactions in ethnic majority students when confronted with issues of racial privilege (Spanierman et al., 2008) and it is possible that some students, particularly those high in color-blind racial attitudes, could perceive aspects of these discussions as racial microaggressions. These considerations are not intended to suggest that multicultural training is contraindicated for ethnic majority students; instead, studies in this area highlight the need for additional research on ways to reduce negative reactivity by ethnic majority students during multicultural training.

Although related to belongingness, experiences of microaggressions were unrelated to perceptions of autonomy for ethnic minority and majority graduate students. These results are surprising given that ethnic majority and ethnic minority students have very different perceptions of race relations on college campuses (Reid \& Radhakrishnan, 2003). One reason a significant correlation between microaggressions and autonomy was not found could be that the graduate students in our study were more intrinsically motivated and autonomous from simply being in a graduate university setting. University settings and especially graduate education settings require students to assert themselves and take control over their academic careers (Faye \& Sharp, 2008). In addition, adults with higher cognitive ability tend to report greater perceptions of autonomy (Ittenbach \& Harrison, 1990).

\section{Emotional Distress and Academic Engagement}

The third goal of this project was to explore the relationship between belongingness, autonomy, emotional distress, and academic engagement. For both ethnic minority and majority graduate students, belongingness was significantly related to academic engagement, and autonomy was found to be a significant predictor of both academic engagement and emotional distress. Consequently, the primary propositions of self-determination theory (i.e., the importance of belongingness and autonomy) held for both groups of school psychology graduate students. These findings support previous research suggesting that a method of increasing students' academic engagement is to increase social support and 
foster feelings of autonomy (Jang, Reeve, \& Deci, 2010; Reeve, Jang, Carrell, Jeon, \& Barch, 2004). Furthermore, these findings support the notion that social and autonomy support have directs effects on psychological well-being, which can also increase student engagement (Steele \& Fullager, 2009). To explore possible critical variables for intervention, the exploratory tests of mediation indicated that experiences of microaggressions are associated with lower academic engagement via lower perceptions of belongingness, and future longitudinal research should directly test this pathway as well as the extent to which graduate programs can have an impact on ethnic minority and majority students' sense of belongingness.

\section{Potential Practical Implications}

Overall, these findings highlight the magnitude of racial microaggressions and social support in academic environments. Of particular note, the statistically significant relations among racial microaggressions, belongingness, and academic engagement were the same across ethnic minority and majority students. This is especially important given the significant association between negative race-related experiences and perceptions of belongingness for graduate students in school psychology programs. If students do not feel that they are socially supported by their peers and professors, they may be less able to maintain adequate levels of psychological adjustment and consequently may be less likely to put forth the effort necessary to achieve academic success (Booker, 2007; Solórzano et al., 2009). Focus groups of African American undergraduate students have indicated that openmindedness and trust among faculty and peers are essential for their success, particularly in the context of classroom discussions concerning race and ethnicity (Booker, 2007). In order to retain ethnic minority students, programs should ensure diverse social and professional activities that foster a sense of belongingness for ethnic minority students throughout their academic career.
Research suggests that students tend to feel more comfortable in their environment when they believe their programs are committed to multicultural sensitivity and diversity (Pope-Davis, Liu, Nevitt, \& Toporek, 2000). Regardless of the specific model of multicultural training in a graduate program, open and respectful discussion of race-related issues is likely to be a critical component. Recent research has highlighted the experiences of faculty and students during "difficult dialogues" in these courses, as well as the role of racial microaggressions in these discussions, and we strongly encourage faculty in school psychology training programs to review this growing literature (e.g., Sue, Lin, Torino, Capodilupo, \& Rivera, 2009; Sue, Rivera, Capodilupo, Lin, $\&$ Torino, 2010; Sue, Torino, Capodilupo, Rivera, \& Lin, 2009). Considering that the ethnic majority graduate students in our sample reported some experiences with racial microaggressions, programs should ensure that multicultural training is not solely focused on ethnic minorities. These courses often highlight White privilege, which subsequently may evoke White guilt (Case, 2007; Todd, Spanierman, \& Aber, 2010). Programs should be aware of potential impacts on ethnic majority students' emotions and sense of social belongingness as well as possible interactions between students' attitudes (i.e., color-blind racial attitudes) and the specific training provided (Chao et al., 2011).

The current study primarily focused on the race-related experiences and adjustment of graduate students in school psychology programs; however, research suggests that perceptions of school racial climate and experiences of racism affect the emotional and academic functioning of school-age youth (Mattison \& Aber, 2007; Sellers, CopelandLinder, Martin, \& Lewis, 2006). In addition, much of the research emphasizing the importance of self-determination theory in academic settings has been conducted with school-age youth (e.g., Van Ryzin et al., 2009). For these reasons, the constructs investigated in this study would also have relevance for school psychologists and others working with schoolage youth. 


\section{Limitations}

One limitation of this study is that data were collected toward the beginning of the fall semester of one academic year, and student perceptions of their program are likely to change over the course of a year. University courses are designed so that most assignments and tests all fall within the same brief time frame-thus students tend to exhibit more stress symptoms during midterms and finals (Weidner, Kohlmann, Dotzauer, \& Burns, 1996). This limitation is particularly relevant because approximately $40 \%$ of the sample was in the first year of graduate training; consequently, these students may have had a limited view of their graduate programs given that they had only been in the program for approximately one month at the time of data collection.

Another limitation is that the measures used to assess graduate student perceptions were self-report measures. Self-report measures sometimes exhibit problems with biased responding in order for people to present themselves in a manner that is socially desirable (Paulhus, 1991). It is possible that the low ratings of emotional distress reported by graduate students in this study were because participants were underreporting their symptoms in order to appear emotionally healthy.

A related concern is that the measure of microaggressions used in this study was initially developed on a sample of African American undergraduate students. Although the wording of items was not group specific, it is possible that group-specific microaggression experiences were overlooked in the measure, which may have limited the number of microaggressions reported by ethnic minority students. Given that over half of the ethnic minority sample was Hispanic American, it is possible that differences between ethnic majority and minority graduate students were minimized because experiences with discrimination vary based on darkness of skin color (Espino \& Franz, 2002); future research should explore this possibility. The measure of racial microaggressions is also limited by combining occurrence vs. nonoccurrence with emotional valence in the response format. This limitation is tempered somewhat by findings that subjective appraisals of life stress are more predictive of emotional distress than counts of stressful life events (Roberts \& Kassel, 1997).

Finally, because participants were recruited via e-mail listservs, we do not have information regarding participant response rates. Although the demographics of study participants appear to be representative of students in school psychology, the sampling strategy employed may limit the generalizability of findings.

\section{Conclusion}

The findings from this study highlight the importance of negative race-related experiences in relation to perceptions of belongingness in school psychology graduate students. Although the major propositions of self-determination theory held for both ethnic majority and minority graduate students and perceptions of microaggressions appeared to be harmful for both groups, some group-specific considerations should be made. Specifically, ethnic minority students experience more racial microaggressions, and additional research is needed to determine the specific experiences that students perceive to be racial microaggressions in the context of graduate training. In the current study, graduate students reported on general experiences of racial microaggressions; consequently, future research is needed to assess the relative importance and impact of microaggression experiences occurring in the graduate program, the larger campus, and the surrounding community. In addition, possible co-occurrence of microaggressions based on gender and sexual orientation should be explored in school psychology graduate students. Such information would facilitate efforts of school psychology graduate faculty to design programs to meet the diverse needs of graduate students.

\section{References}

Ahrens, C., \& Ryff, C. (2006). Multiple roles and wellbeing: Sociodemographic and psychological modera- 
tors. Sex Roles, 55, 801-815. doi:10.1007/s11199-0069134-8

Booker, K. (2007). Perceptions of classroom belongingness among African American college students. College Student Journal, 41, 178-186.

Boulet, J., \& Boss, M. W. (1991). Reliability and validity of the Brief Symptom Inventory. Psychological Assessment, 3, 433-437. doi:10.1037/1040-3590.3.3.433

Burney, J., Celeste, B., Johnson, J., Klein, K., Nordal, K., \& Portnoy, S. (2005). Mentoring professional psychologists: Programs for career development, advocacy, and diversity. Professional Psychology: Research and Practice, 40, 292-298. doi:10.1037/a0015029

Case, K. (2007). Raising White privilege awareness and reducing racial prejudice: Assessing diversity course awareness. Teaching of Psychology, 34, 231-235. doi: 10.1080/00986280701700250

Chao, R. C., Wei, M., Good, G. E., \& Flores, L. Y. (2011). Race/ethnicity, color-blind racial attitudes, and multicultural counseling competence: The moderating effects of multicultural counseling training. Journal of Counseling Psychology, 58, 72-82. doi:10.1037/ a0022091

Chen, F. (2007). Sensitivity of goodness of fit indexes to lack of measurement invariance. Structural Equation Modeling, 14, 464-504.

Cheung, G. W., \& Lau, R. S. (2008). Testing mediation and suppression effects of latent variables: Bootstrapping with structural equation models. Organizational Research Methods, 11, 296-325. doi:10.1177/ 1094428107300343

Coffman, D. L., \& MacCallum, R. C. (2005). Using parcels to convert path analysis models into latent variable models. Multivariate Behavioral Research, 40, 235-259. doi:10.1207/s15327906mbr4002_4

Cohen, J. (1988). Statistical power analysis for the behavioral sciences (2nd ed.). Hillsdale, NJ: Erlbaum.

Cohen, S., Kamarck, T., \& Melstein, R. (1983). A global measure of perceived stress. Journal of Health and Social Behavior, 24, 385-396. doi:10.2307/2136404

Cohen, S., \& Williamson, G. (1988). Perceived stress in a probability sample of the United States. In S. Spacapan \& S. Oakamp (Eds.), The social psychology of health (pp. 31-67). Newbury Park, CA: Sage.

Curtis, M. J., Lopez, A. D., Castillo, J. M., Batsche, G. M., Minch, D., \& Smith, J. C. (2008). The status of school psychology: Demographic characteristics, employment conditions, professional practices, and continuing professional development. Communiqué, 36(5), 27-29.

Davidson, M., \& Foster-Johnson, L. (2001). Mentoring in the preparation of graduate researchers of color. $R e$ view of Educational Research, 71, 549-574. doi: 10.3102/00346543071004549

Davis, L., Johnson, S., Cribbs, J., \& Saunders, J. (2002). A brief report: Factors influencing African American youth to stay in school. Journal of Adolescent Research, 17, 223-243. doi:10.1177/0743558402173001

Davis, A., McIntosh, D., Phelps, L., \& Kehle, T. (2004). Addressing the shortage of school psychologists: A summative overview. Psychology in the Schools, 41, 489-495. doi:10.1002/pits. 10192

Deci, E., Vallerand, R., Pelletier, L., \& Ryan, R. (1991). Motivation and education: The self-determination perspective. Educational Psychologist, $3 \& 4,325-346$. doi:10.1207/s15326985ep2603\&4_6
Derogatis, L. R. (1975). Brief symptom inventory. Baltimore, MD: Clinical Psychometric Research.

Derogatis, L. R., \& Melisaratos, N. (1983). The Brief Symptom Inventory: An introductory report. Psychological Medicine, 13, 595-605. doi:10.1017/ S0033291700048017

Enders, C. K. (2010). Applied missing data analysis. New York: Guilford Press.

Espino, R., \& Franz, M. M. (2002). Latino phenotypic discrimination revisited: The impact of skin color on occupational status. Social Science Quarterly, 83, 612623. doi:10.1111/1540-6237.00104

Fagan, T. K. (1988). The historical improvement of the school psychology service ratio: Implications for future employment. School Psychology Review, 17, 447458.

Faye, C., \& Sharpe, D. (2008). Academic motivation in university: The role of basic psychological needs and identity formation. Canadian Journal of Behavioural Science, 40, 189-199. doi:1037/a0012858

Fredricks, J. A., Blumenfeld, P. C., \& Paris, A. H. (2004). School engagement: Potential of the concept, state of the evidence. Review of Educational Research, 74, 59-109. doi:10.3102/00346543074001059

Handelsman, M. M., Briggs, W. L., Sullivan, N., \& Towler, A. (2005). A measure of college student course engagement. Journal of Educational Research, 98, 184-191. doi:10.3200/JOER.98.3.184-192

Hu, L., \& Bentler, P. M. (1999). Cutoff criteria for fit indexes in covariance structure analysis: Conventional criteria versus new alternatives. Structural Equation Modeling, 6, 1-55. doi:10.1080/10705519909540118

Hwang, W., \& Goto, S. (2008). The impact of perceived racial discrimination on the mental health of Asian American and Latino college students. Cultural Diversity and Ethnic Minority Psychology, 14, 326-335. doi:10.1037/1099-9809.14.4.326

Ittenbach, R. F., \& Harrison, P. L. (1990). Predicting ego-strength from problem-solving ability of college students. Measurement and Evaluation in Counseling and Development, 23, 128-136.

Jang, H., Reeve, J., \& Deci, E. L. (2010). Engaging students in learning activities: It is not autonomy support or structure but autonomy support and structure. Journal of Educational Psychology, 102, 588-600. doi:10.1037/a0019682

Johnson, D., Johnson, R., Buckman, L., \& Richards, P. (1985). The effect of prolonged implementation of cooperative learning on social support in the classroom. Journal of Psychology, 119, 403-411.

Kanner, A. D., Coyne, J. C., Schaefer, C., \& Lazarus, R. S. (1981). Comparison of two modes of stress measurement: Daily hassles and uplifts versus major life events. Journal of Behavioral Medicine, 4, 1-39. doi:10.1007/BF00844845

Lambert, S. F., Herman, K. C., Bynum, M. S., \& Ialongo, N. S. (2009). Perceptions of racism and depressive symptoms in African American adolescents: The role of perceived academic and social control. Journal of Youth and Adolescence, 38, 519-531. doi:10.1007/ s10964-009-9393-0

Little, T. D., Cunningham, W. A., Shahar, G., \& Widaman, K. F. (2002). To parcel or not to parcel: Exploring the question, weighing the merits. Structural Equation Modeling, 9, 151-173. doi:10.1207/ S15328007SEM0902_1 
Locks, A., Hurtado, S., Bowman, N., \& Oseguera, L. (2007). Extending notions of campus climate and diversity to students' transition to college. The Review of Higher Education, 31, 257-285.

Lubke, G. H., \& Dolan, C. V. (2003). Can unequal residual variances across groups mask differences in residual means in the common factor model? Structural Equation Modeling, 10, 175-192. doi:10.1207/ S15328007SEM1002_1

MacKinnon, D. P., Lockwood, C. M., \& Williams, J. (2004). Confidence limits for the indirect effect: Distribution of the product and resampling methods. Multivariate Behavioral Research, 39, 99-128. doi: 10.1207/s15327906mbr3901_4

Mattison, E., \& Aber, M. S. (2007). Closing the achievement gap: The association of racial climate with achievement and behavioral outcomes. American Journal of Community Psychology, 40, 1-12. doi:10.1007/ s10464-007-9128-X

Mercer, S. H., Zeigler-Hill, V., Wallace, M., \& Hayes, D. M. (2011). Development and initial validation of the Inventory of Microaggressions Against Black Individuals. Journal of Counseling Psychology, 58, 457469. doi:10.1037/a0024937

Muthén, L. K., \& Muthén, B. O. (1998-2010). Mplus user's guide (6th ed.). Los Angeles: Author.

National Association of School Psychologists. (2010). NASP-approved/nationally-recognized graduate programs in school psychology. Retrieved from http:// www.nasponline.org/certification/ApprovedPrograms 0603.pdf

Nevitt, J., \& Hancock, G. R. (2001). Performance of bootstrapping approaches to model test statistics and parameter standard error estimation in structural equation modeling. Structural Equation Modeling, 8, 353377. doi:10.1207/S15328007SEM0803_2

Paulhus, D. L. (1991). Measurement and control of response bias. In J. P. Robinson, P. R. Shaver, \& L. S. Wrightsman (Eds.), Measures of personality and social psychological attitudes (pp. 17-59). San Diego, CA: Academic Press.

Pierce, C. M. (1969). Is bigotry the basis of the medical problems of the ghetto? In J. C. Norman (Ed.), Medicine in the ghetto (pp. 301-312). New York: Meredith.

Pope-Davis, D., Liu, W., Nevitt, J., \& Toporek, R. (2000). The development and initial validation of the Multicultural Environmental Inventory: A preliminary investigation. Cultural Diversity and Ethnic Minority Psychology, 6, 57-64, doi:10.1037//1099-9809.6.1.57

Reeve, J., Jang, H., Carrell, D., Jeon, S., \& Barch, J. (2004). Enhancing students' engagement by increasing teachers' autonomy support. Motivation and Emotion, 28, 147-169. doi:10.1023/B:MOEM.0000032312.95499.6f

Reid, L. D., \& Radhakrishnan, P. (2003). Race matters: The relation between race and general campus climate. Cultural Diversity and Ethnic Minority Psychology, 9, 263-275. doi:10.1037/1099-9809.9.3.263

Roberts, J. E., \& Kassel, J. D. (1997). Labile self-esteem, life stress, and depressive symptoms: Prospective data testing a model of vulnerability. Cognitive Therapy and Research, 21, 569-589.

Ryff, C. (1989). Happiness is everything, or is it? Explorations on the meaning of psychological well-being. Journal of Personality and Social Psychology, 57, 1069-1081. doi:10.1037/0022-3514.57.6.1069
Ryff, C., \& Keyes, C. (1995). The structure of psychological well-being revisited. Journal of Personality and Social Psychology, 69, 719-727. doi:10.1037/ 0022-3514.69.4.719

Ryff, C. D., \& Singer, B. H. (2006). Best news yet on the six-factor model of well-being. Social Science Research, 35, 1103-1119. doi:10.1016/j.ssresearch. 2006.01.002

Schacht, T. E. (2008). A broader view of racial microaggression in psychotherapy. American Psychologist, 63, 273. doi:10.1037/0003-066X.63.4.273

Schmutte, P., \& Ryff, C. (1997). Personality and well being: Reexamining methods and meanings. Journal of Personality and Social Psychology, 73, 549-559. doi: 10.1037/0022-3514.73.3.549

Sellers, R. M., Copeland-Linder, N., Martin, P. P., \& Lewis, R. (2006). Racial identity matters: The relationship between racial discrimination and psychological functioning in African American adolescents. Journal of Research on Adolescence, 16, 187-216. doi: 10.1111/j.1532-7795.2006.00128.x

Shelton, K., \& Delgado-Romero, E. A. (2011). Sexual orientation microaggressions: The experience of lesbian, gay, bisexual, and queer clients in psychotherapy. Journal of Counseling Psychology, 58, 210-221. doi: 10.1037/a0022251

Smith, W., Allen, W., \& Danley, L. (2007). “Assume the position...you fit the description": Psychosocial experiences and racial battle fatigue among African American male college students. American Behavioral Scientist, 51, 551-578. doi:10.1177/0002764207307742

Solórzano, D., Ceja, M., \& Yosso, T. (2009). Critical race theory, racial microaggressions, and campus racial climate: The experiences of African American college students. Journal of Negro Education, 69, 60-73.

Spanierman, L., Euna, O., Poteat, V., Hund, A., McClair, V., Beer, A., et al. (2008). White university students' responses to societal racism: An qualitative investigation. The Counseling Psychologist, 36, 839-870. doi: $10.1177 / 0011000006295589$

Steele, J., \& Fullager, C. (2009). Facilitators and outcomes of student engagement in a college setting. Journal of Psychology, 14, 5-27. doi:10.3200/ JRLP.143.1.5-27

Sue, D. W. (2010). Microaggressions, marginality, and oppression: An introduction. In D. W. Sue (Ed.), Microaggressions and marginality: Manifestation, dynamics, and impact (pp. 3-24). Hoboken, NJ: Wiley.

Sue, D. W., Bucceri, J., Lin, A., Nadal, K., \& Torino, G. (2009). Racial microaggressions and the Asian American experience. Asian American Journal of Psychology, S, 88-101. doi:10.1037/1948-1985.S.1.88

Sue, D. W., Capodilupo, C., \& Holder, A. (2008). Racial microaggressions and the life experiences of African Americans. Professional Psychology: Research and Practice, 39, 329-336. doi:10.1037/ 0735-7028.39.3.329

Sue, D. W., Capodilupo, M., Torino, G., Bucceri, A., Holder, M., Nadal, K., et al. (2007). Racial microaggressions in everyday life: Implications for clinical practice. American Psychologist, 62, 271-286. doi: 10.1037/0003-066X.62.4.271

Sue, D., Lin, A. I., Torino, G. C., Capodilupo, C. M., \& Rivera, D. P. (2009). Racial microaggressions and difficult dialogues on race in the classroom. Cultural 
Diversity and Ethnic Minority Psychology, 15, 183190. doi:10.1037/a0014191

Sue, D. W., Nadal, K., Capodilupo, M., Lin, A., Torino, G., \& Rivera, D. (2008). Racial microaggressions against Black Americans: Implications for counseling. Journal of Counseling and Development, 86, 330-338.

Sue, D., Rivera, D. P., Capodilupo, C. M., Lin, A. I., \& Torino, G. C. (2010). Racial dialogues and White trainee fears: Implications for education and training. Cultural Diversity and Ethnic Minority Psychology, 16, 206-214. doi:10.1037/a0016112

Sue, D. W., Torino, G. C., Capodilupo, C. M., Rivera, D. P., \& Lin, A. I. (2009). How White faculty perceive and react to difficult dialogues on race: Implications for education and training. The Counseling Psychologist, 37, 1090-1115. doi:10.1177/0011000009340443

Thomas, K. R. (2008). Macrononsense in multiculturalism. American Psychologist, 63, 274-275. doi: 10.1037/0003-066X.63.4.274

Thompson, V., \& Alexander, H. (2006). Therapists' race and African American clients' reactions to therapy. Psychotherapy: Theory, Research, Practice, Training, 43, 99-110. doi:10.1037/0033-3204.43.1.99

Todd, N., Spanierman, L., \& Aber, M. (2010). White students reflecting on Whiteness: Understanding emotional responses. Journal of Diversity in Higher Education, 3, 97-110. doi:10.1037/a0019299

Utsey, S. O. (1999). Development and validation of a short form of the Index of Race-Related Stress (IRRS)—Brief Version. Measurement and Evaluation in Counseling and Development, 32, 149-167.

Van Ryzin, M. J., Gravely, A. A., \& Roseth, C. J. (2009). Autonomy, belongingness, and engagement in school as contributors to adolescent psychological well-being.
Journal of Youth and Adolescence, 38, 1-12. doi: 10.1007/s10964-007-9257-4

Vasquez, M., Lott, B., Garcia-Vasquez, E., Grant, S., Iwamasa, G., Molina, L., et al. (2006). Barriers and strategies in increasing diversity in psychology. American Psychologist, 61, 157-172. doi:10.1037/0003066X.61.2.157

Walton, G., \& Cohen, G. (2007). A question of belonging: Race, social fit, and achievement. Journal of Personality and School Psychology, 92, 82-96. doi:10.1037/ 0022-3514.92.1.82

Weidner, G., Kohlmann, C., Dotzauer, E., \& Burns, L. (1996). The effects of academic stress on health behaviors in young adults. Anxiety, Stress, \& Coping: An International Journal, 9, 123-133. doi:10.1080/ 10615809608249396

Yeh, M., Eastman, K., \& Cheung, M. (1994). Children and adolescents in community health centers: Does the ethnicity or the language of the therapist matter? Journal of Community Psychology, 22, 153-163. doi:10.1002/1520-6629(199404)22:2<153::AID-JCOP 2290220210>3.0.CO;2-R

Yosso, T. J., Smith, W. A., Ceja, M., \& Solórzano, D. G. (2009). Critical race theory, racial microaggressions, and campus racial climate for Latina/o undergraduates. Harvard Educational Review, 79, 659-690.

Zhou, Z., Bray, M., Kehle, T., Theodore, L., Clark, E., \& Jenson, W. (2004). Achieving ethnic minority parity in school psychology. Psychology in the Schools, 41, 443-450. doi:10.1002/pits.10187

Date Received: June 28, 2011

Date Accepted: December 15, 2011

Action Editor: Cynthia Anderson

Chelsi R. Clark, MS, is a graduate student in the Department of Psychology at The University of Southern Mississippi. Her research interests include identifying appropriate academic interventions for youth at risk for academic failure and identifying methods to increase cultural and linguistic competence in the field of school psychology.

Sterett H. Mercer, $\mathrm{PhD}$, is an assistant professor in the Department of Educational and Counselling Psychology and Special Education at the University of British Columbia. His research interests include methods to improve judgment and decision making using curriculum-based academic measures, as well as the impact of classroom contextual factors (e.g., teacher-student relationship quality, social norms, and peer relationships) on student functioning.

Virgil Zeigler-Hill, $\mathrm{PhD}$, is an assistant professor in the Department of Psychology at Oakland University. He is a social-personality psychologist with research interests that include self-esteem, narcissism, and interpersonal relationships.

Brad A. Dufrene, $\mathrm{PhD}$, is an associate professor in the Department of Psychology at The University of Southern Mississippi. His research interests include the treatment utility of functional assessment and behavioral consultation in applied settings. 